\title{
MULHERES INDÍGENAS E DITADURA MILITAR BRASILEIRA
}

\section{JHEUREN KAROLINE COSTA DE SOUZA ${ }^{1}$}

$U F P A$

RESUMO: Este artigo discute como as mulheres indígenas são representadas nos Relatório Figueiredo ${ }^{2}$ e no Relatório Final da Comissão Nacional da Verdade ${ }^{3}$ e a necessidade de visibilidade para elas, baseando-se no estudo de autoras e autores decoloniais que entendem a interseccionalidade raça, gênero e etnia como chave para compreensão e análise das violências que sistematicamente afetam mulheres indígenas. A discussão é importante para se pensar as violações de forma diferenciada e assim produzir a possibilidade de mudanças teóricometodológicas, as quais são fundamentais à escrita da história indígena sobre o período da ditadura militar brasileira.

PALAVRAS-CHAVE: direitos humanos; povos indígenas; violações de direitos; ditadura; mulheres indígenas.

ABSTRACT: This article discusses how Indigenous women are represented in the Figueiredo Report and in the Final Report of the National Commission of Truth in Brazil, and the necessity of visibility for these women, based on the study of decolonial authors who understand the intersectionality between race, gender and ethnicity as key to the comprehesion and analysis of the violence that systematically affects Indigenous women. The discussion is important to consider violations in a differentiated way and therefore produce the possibility of theoretical and methodological changes, which are fundamental to the writing of Indigenous history concerning the period of the Brazilian military dictatorship.

KEYWORDS: human rights; Indigenous peoples; violations of rights; dictatorship, Indigenous women.

\footnotetext{
${ }^{1}$ Bolsista de Iniciação Científica- CNPQ/ UFPA, discente do curso de Ciências Sociais da Universidade Federal do Pará (UFPA). Email: jheurensouza04@.gmailcom.

${ }^{2}$ Relatório Figueiredo é um documento de 7000 páginas, as quais mostram violações de latifundiários e do Estado para com os índios brasileiros, produzido em 1967, pelo procurador Jader de Figueiredo Correa. O relatório esteve desaparecido durante décadas e acreditava-se que tivesse queimado em um incêndio no Ministério da Agricultura em junho de 1967, mas ele foi encontrado no Museu do índio em 2012, por Marcelo Zelic.

${ }^{3}$ O Relatório da Comissão Nacional da Verdade é um documento que mostra as violações de Direitos Humanos no período ditatorial, como uma denúncia contra o Estado e seus agentes. Para este trabalho deuse especial atenção ao capítulo que trata especificamente de Violações de Direitos Humanos dos Povos Indígenas, elaborado por Maria Rita Kehl.
} 
A discussão sobre mulheres indígenas e ditadura militar brasileira está muito além de uma discussão somente sobre gênero. A questão central consiste em pensar essas mulheres como indivíduos colonizados e marginalizados pelo poder dominante. Compreendo tais mulheres como subalternizadas, na definição apresentada por Spivak (1998): as camadas mais baixas da sociedade constituídas pelos modos específicos de exclusão dos mercados, da representação política e legal, e da possibilidade de se tornarem membros plenos no estrato social dominante.

Está além do ser mulher, pois os recortes interseccionais perpassam gênero, raça e etnia. As mulheres indígenas são subjugadas por três tipos de opressão, como perceberemos ao longo da análise dos documentos. E elas vivenciam violência epistêmica, termo usado por Spivak, que consiste na tática de neutralização do Outro, tirando qualquer possibilidade de representação, silenciando-o. Pois mesmo quando são violadas não lhes é dada devida possibilidade de falar sobre essas violências e de tratá-las de forma específica e diferenciada da sofrida pelos homens indígenas.

Assim, na questão da subalternidade feminina, penso a marginalização dessa mulher no cenário da produção colonial dominado pelo homem branco, estrangeiro e heterossexual. O ser mulher que se encara na discussão feminista europeia não integra essas mulheres indígenas como sujeitos violados, pois percebe apenas um coletivo homogêneo, noção que será duramente combatida pelos autores e autoras de estudo decolonial.

Dentre as autoras que discutem gênero na colonialidade, temos Maria Lugones, enquanto mulher Argentina/ Latina, residente nos Estados Unidos que pensa a interseccionalidade entre raça, classe, gênero e sexualidade para entender a indiferença dos homens para com as violências que sistematicamente acontecem com as "mulheres de cor", as mulheres vítimas da colonialidade - e nisto inclui mulheres indígenas. Lugones cria conceito Sistema Colonial Moderno de Gênero, o qual explica as violações de gênero posteriores ao período colonial serem tão semelhantes às que aconteceram na "conquista das Américas". Dessa forma, mulheres indígenas estão postas sendo violadas e pensadas em suas particularidades. 
Compreender as particularidades e a persistência da colonialidade mesmo após o colonialismo é chave para entender a posição dessas mulheres indígenas nos anos 1967, escrita do Relatório Figueiredo e 2014, nas denúncias da Comissão Nacional da Verdade:

A colonialidade se refere a um padrão de poder que emerge como resultado do colonialismo moderno, mas em vez de estar limitado a uma relação formal de poder entre os povos ou nações, também se refere a forma como o trabalho, o conhecimento, a autoridade e as relações intersubjetivas se articulam entre si, através do mercado capitalista mundial e da ideia de raça. Assim, pois, embora o colonialismo preceda a colonialidade, a colonialidade sobrevive ao colonialismo. A mesma se mantém viva em manuais de aprendizado, no critério para um bom trabalho acadêmico, na cultura, no sentido comum, na auto-imagem dos povos, nas aspirações dos sujeitos e em tantos outros aspectos de nossa experiência moderna. Em um sentido, respiramos a colonialidade na modernidade cotidianamente (MALDONADO-TORRES, 2003, p. 131).

Nelson Maldonado-Torres (2003) afirma que, quando os europeus chegaram à América, não aplicaram o código ético que regulava a vida em seus reinados, mas sim um código de guerra para com os povos nativos, dessa forma suas ações eram regulamentadas pela "ética de guerra". Logo, o racismo moderno é a radicalização e naturalização da ética de guerra. E esta ética vai incluir práticas de eliminação e escravização de certos sujeitos, como indígenas e negros, em um processo empresarial da colonização que persiste na modernidade, insisto. O autor diz que a mulher é o objeto "privilegiado" dessa violação, pois são entendidas como sujeitos fundamentalmente penetráveis e sexualmente racializados. Logo, o controle simbólico e literal dos corpos dos indígenas é importante na guerra contra os mesmos.

Outra autora que discute a relação da violência sexual e colonialismo é Ann Stoler (1997 apud SMITH, 2014). Para ela, o racismo é uma parte permanente do tecido da sociedade e se configura em uma tática de criar inimigos internos "biologizados" contra os quais a sociedade precisa lutar. Observa ainda que no Estado moderno, a purificação e eliminação de inimigos raciais garantem o crescimento do corpo nacional. Afirma que "o racismo não emerge somente em épocas 
de crise, em limpezas esporádicas. É um elemento interno do Estado biopolítico, tecido na trama do corpo social, tramado no seu próprio tecido. (p. 197).

Anibal Quijano (2000) afirma ainda que essa racialização moderna é baseada em uma colonialidade do poder, que orienta ações desde o período colonial até os dias atuais:

A globalização em curso, vem em primeiro lugar, da culminação de um processo que começou com a constituição da América e do capitalismo colonial/ moderno e eurocentrado como um novo padrão de poder mundial. Um dos eixos fundamentais desse padrão de poder é a classificação social da população mundial sobre a ideia de raça, uma construção mental que expressa a experiência básica da dominação colonial e que desde então permeia as dimensões mais importantes do poder mundial, incluindo sua racionalidade específica, o eurocentrismo (p. 201).

Essa relação de colonialidade persistindo na modernidade e tendo fortes referências estatais para mantê-la tem como exemplo o período ditatorial brasileiro, na perseguição aos povos indígenas, os quais eram vistos como empecilhos para o progresso econômico.

Partindo da ideia de quase invisibilização das mulheres indígenas, atento para o que Camille Castelo Branco Barata, que trabalha com corporeidades silenciadas, sofrimentos e politização das mulheres Tembé Tenetehara, afirma: "[n]esse sentido, o silêncio referido no título do capítulo não é uma condição ontológica das mulheres, não surge do nada e sim é engendrado por um projeto de terror colonial" (2017, p. 15).

Entendo que o terror colonial persiste e que as marcas dessa colonização foram reproduzidas nos anos da ditadura e continuam até os dias atuais. Com isso estabeleço um diálogo com essa questão decolonial, a qual explica as opressões atuais pautadas em uma continuidade e ressignificadas a partir de uma modernização. Mario Rodríguez Ibáñez, integrante da equipe de Wayna Tambo - Casa juvenil das Culturas, na Bolívia -, trata dessa questão em torno da modernização das cidades e exclusão do indígena daquele meio:

[A]s cidades são o coração da reprodução dos modos de vida dominante, colonial, moderno, capitalista. As cidades são o lugar onde se alimentam as subjetividades 
que consolidam nosso histórico saque e o extrativismo primário que condenou a colônia. $\mathrm{E}$, no entanto, nossas cidades não escapam de seu destino; não podem ser habitadas por nossos outros modos de vida profundamente indígenas ou originários, que disputam desde o popular seus significados e configurações (RODRÍGUEZ IBÁÑEZ, 2013, p. 225).

Essa reprodução dos modos de vida dominante perpetua sistemas que há muito se acredita serem ultrapassados, em suma. O ser latinoamericana é apagado constantemente nos lugares das falas referentes ao ser mulher, latina, indígena e traz subjetividades negadas e esquecidas pelo poder hegemônico. Esse "apagamento" é mostrado nos inúmeros trabalhos feitos sobre o tema, inclusive nos documentos abaixo analisados.

\section{O Relatório Figueiredo e as mulheres indígenas}

Centrei minha análise na síntese que o Procurador Geral da República, Jáder de Figueiredo, encaminhou ao Ministério do Interior, a qual consiste no nome dos funcionários envolvidos nos crimes denunciados. Destaquei as violações de gênero por ser objeto central desta pesquisa, mas não desconsidero todas as outras atrocidades que foram cometidas contra homens indígenas. Atento para os termos e categorias empregados à época. Apesar da pouca especificidade dada às violências de gênero no Relatório, ainda é possível trabalhá-las.

No relato abaixo, início da síntese, é bem nítida a gravidade das violências contra as mulheres - destacada inclusive pelo procurador como "desumanas".

Isso porque, de maneira pral, não se respeitava o indígena como pessoa humana, servindo homens e mulheros, como animais de carga, cujo trabalho deve reverter ao funcionário. No caso da mulher torna-se mals revoltante porque as condições eram mais de sumanas.

Fonte: RF Síntese, p. 3, grifos meus 


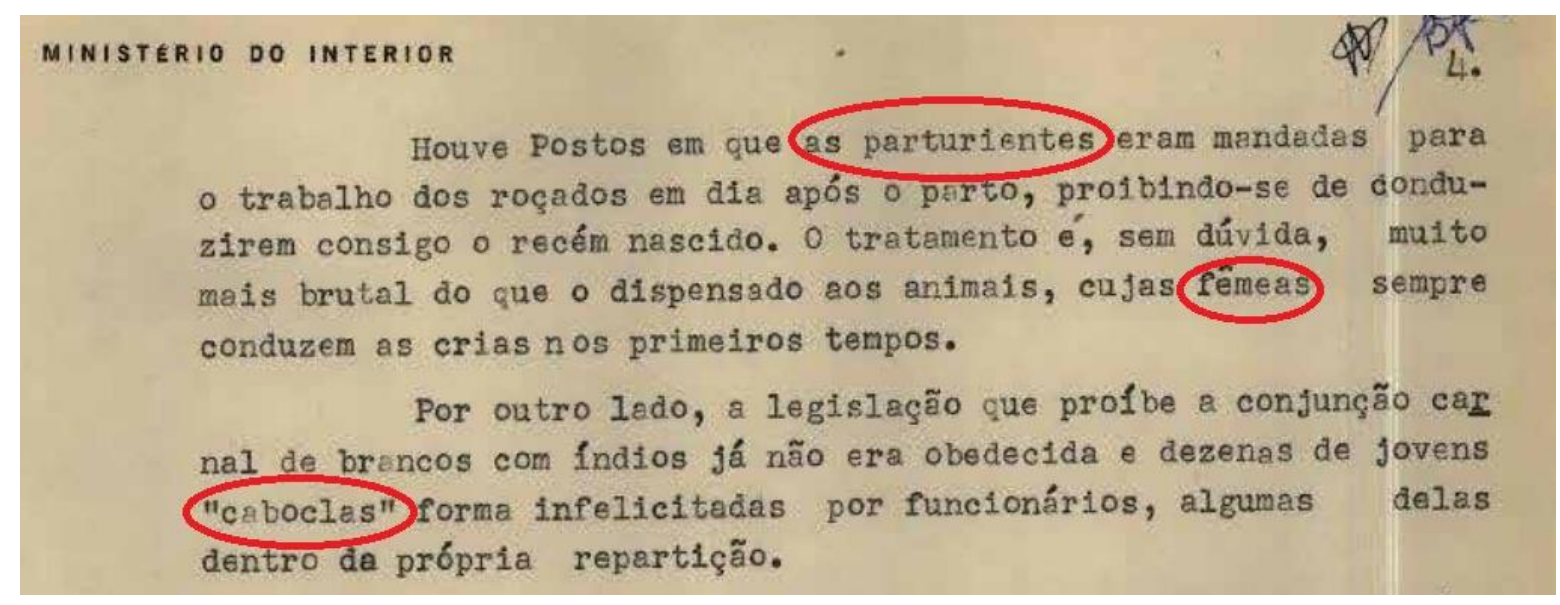

Fonte: RF Síntese, p. 4, grifos meus

Sobre os crimes gerais contra a pessoa e a propriedade do índio, Figueiredo destaca que muitas indígenas estavam sendo prostituídas. Não ficam explicitas as formas como essa prostituição se dava, mas pela análise dos crimes e dos relatos, dificilmente seria por livre e espontânea vontade dessas mulheres, como afirma Mariana Joffily (2016), quando trabalha violências sexuais nas ditaduras militares latino-americanas:

Um dos grandes problemas do delito sexual reside no fato de a suspeita também recair sobre a pessoa afetada. Se os sobreviventes de situações extremas carregaram a culpa por não terem vivido o mesmo destino de seus companheiros mortos ou desaparecidos, quem sofreu violência sexual teve dificuldade de subtrair-se de um sentimento de responsabilidade pela experiência traumática, o que tendeu a isolá-las no âmbito do privado e da vergonha (p. 167).

Assim, pensar a prostituição de mulheres indígenas por agentes do órgão é apontar o quão arbitrária foi a atuação do $\mathrm{SPI}^{4}$. Não se pode esquecer também a particularidade do Relatório ter sido escrito por um homem, refletindo seu ponto de vista sobre o ocorrido. O que ele entendeu por prostituição tem raízes mais profundas e implicações maiores nas identidades dessas mulheres. Abaixo temos outro relato com o termo "prostituição":

\footnotetext{
${ }^{4}$ O Serviço de Proteção aos Índios e Localização dos Trabalhadores Nacionais (SPILTN, a partir de 1918 apenas SPI) foi criado, a 20 de junho de 1910, pelo Decreto № 8.072, tendo por objetivo prestar assistência a todos os índios do país.
} 
1- CRTMES CONTRA A PESSOA E A PROPRIEDADE DO INDIO

1.1 - Assassinatos de Indios (Individuais o coletivos: tribos)

1.2 - Prostituição de Indias

1.3 - Sevícias

1.4 - Trabalho escravo

1.5 - Usurpação do trabalho do Indio

1.6 - Apropriação e desvio de recursos oriundos do patrimônio Indígena

1.7 - Dilapiđação do patrimônio indígena:

a) venda de gado

b) arrendamento de terras

c) venda de madeiras

Fonte: RF Síntese, p. 6, grifos meus

Os Kadiueus (antigos Gualacurús), donos das ricas terras que Ihes deu o Senhor D. Pedro II pela decisiva ajuda à tropas brasileiras naquela região durante a Guerra do Paraguai, sentem-se escorraçados em seus domínios, o seu gado vendido e suas mulheres pros tituídas.

Fonte: RF Síntese, p. 9, grifos meus

Abordo as violências enumeradas por nome de agressor, respectivamente, como Jáder de Figueiredo enviou no documento. Apesar de nominar os indivíduos causadores dessa violência, atento que a questão é mais ampla do que parece. Pois pensar tais violações somente do ponto de vista privado isola essas mulheres violadas, como afirma Joffily (2016). Ou seja, é necessário compreender essas violências a partir de um espectro amplo, tomadas como violências do Estado brasileiro para com essas pessoas e entendê-las como acontecimentos de ordem política, não individual.

Ela destaca ainda que na América Latina, como exemplo a Guatemala, a ditadura assume proporções de genocídio étnico, empregando a violência sexual em larga escala para com mulheres indígenas: 
Esse tipo de padrão repressivo era compartilhado tanto por mulheres indígenas como ladinas (não indígenas), e foram executadas por diferentes organismos do Estado: exército, polícia nacional, polícia judiciária, etc. E também por agentes não estatais, mas protegidos pelo Estado, como os esquadrões da morte, grupos paramilitares e milícias (GONZÁLEZ, apud JOFFILY, 2016).

\section{ATASES INÁCTO CARDOSO \\ 1. Aliciamento da India Lconora, da tribo Tucanos, do alto do Rio Negro, para amente de Manoel Moroira de Araújo (11. 345). \\ 2 - Assinou reoibos falsos para efeito de fraude da Menda Indf́gena, por Manocl Moreira de Araújo, na IR-1 (fl. 4026).}

Fonte: RF Ssíntese, p. 19, grifos meus

Outra questão que me chama atenção na leitura do Relatório são as categorias usadas para caracterizar as violências de gênero, dentre elas: aliciamento, sedução, defloração, infelicitação, desrespeito, entre outras. Atentando para o contexto social e político da época e para o autor do documento, entende-se porque questões graves são tratadas em termos tão amenos. É necessário que falemos de estupro, abusos, assédios de maneira a compreender o quão insidiosas foram as ações da ditadura sobre as mulheres indígenas. Faz-se preciso tratar de questões como etnocídio e genocídio, pautados em um projeto "desenvolvimentista" que extermina e massacra, sobretudo mulheres, de forma contínua.

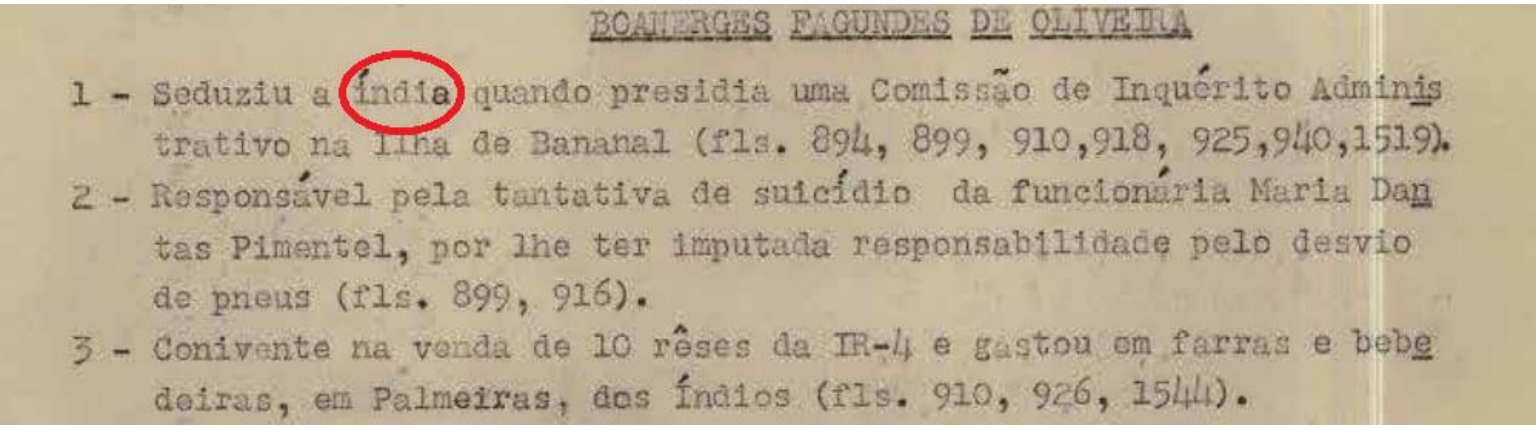

Fonte: RF Síntese, p. 20, grifos meus 


\section{DJALMA MONGTENOT}

1 - Deflorou a Indía Terena do Pôsto Indígena Ipegue, no própria Io einto da sede da Inspetoria (fls. $3770,3773,3784)$.

2 - Inriquecimento ilícito . Possui vérios eaminhões adquiridos sem melos legais aparentes ( 11.337 ).

Fonte: RF Síntese, p. 24, Grifos meus

Deflorar implica em tirar a virgindade. Nesta denúncia percebemos que nem as moças virgens passavam ilesas aos abusos sexuais. É revoltante que o órgão que deveria garantir direitos básicos aos indígenas tenha chegado a tal ponto.

\section{ELITA FBRREIRA STMÕES}

1 - Espancou duas (indias) e é responsável pelo desaparecimento de uma delas no Pósto Indígena Vanuire (fl. 1566).

2 - Irresponsabilidade funcional: como professôra nunca deu aula - no Pôsto Inaígena Vanuire, onde era lotada (f1. 1682).

Fonte: RF Síntese, p. 26, grifos meus

ÉRICO

SAMPAIO

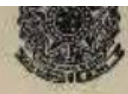

MINISTERIO DO INTERIOR

27.

6a IR, para trabainos gratuitos em cagsa de femílias de projeção como castigo (f1. 1506).

11 - Idem, idem, nos casos de crimes de estupro. morte, espancamento, contra os ínicios, fatos comunicaios aquela Diretoria sem que fôs se tomada nenhuma providência (fls. 1506).

12- Corresponsável por pagamento ilegal dos vencimentos da falecida esposa de Luiz Martins da Cunha, por mais de um ano (fl. L011).

Fonte: RF Síntese, p. 26, grifos meus 


\section{PLÁVIO DE ABREU}

1 - Escravização de fndios em proveito próprio (fls. $1513,1680,1791$ )

2 - Embolsou a importâncla referente do pagame to de serviço executado pelos fndios na Fazenda do Sr. Luiz Gonçalves (fl. 1513),

3 - Trocou a ind1a Rosa por um fogão de barro com o Sr. Seabra e ainda mandou surrar o pai da mesma, em virtude da reclamação fel ta (fls. 1680, 4288, 1683).

4 - Responsável pelo espancamento do f́naio Cecilo de 7 anos de idade (fls. 1680, 4255). Idem do garoto índio Lalico (fls. 1789,1791, 1681).

5 - Maus tratos aos Indios (fls. 1574, 1680, 1683, 1414).

6 - Costumava forçar os fndios a espacarem suas maes, tendo castiga do o fndio Salu, por ter se negado a tal ( $\mathrm{fl}$. 1680) e da (nndia) Carolina ( $f 1.4287$ ).

Fonte: RF Síntese, p. 27, grifos meus

Esse episódio é narrado por Rubens Valente, em seu livro Os Fuzis $e$ as Flechas ${ }^{6}$. O autor afirma que Rosa era indígena bororo e que foi entregue por Flávio de Abreu a um vizinho "civilizado", o Seabra. Tudo feito em troca da construção de um fogão de barro. Rosa, provavelmente, era muito jovem, pois a "seleção" foi feita entre as meninas índias que frequentavam a escola. E que após a conclusão do fogão, a menina índia é devolvida ao pai, inconformado" (VALENTE, 2017). Esse depoimento foi dado por Juracy, servidora do Posto indígena. A mulher afirma que estranhou o fato da inexistência de crianças indígenas e que a mortalidade infantil fosse tão grande. Após apurar os motivos, Juracy descobre que Abreu obrigava as mulheres índias ao cumprimento de tarefas rurais, mesmo se estivessem amamentando seus filhos. E tal atrocidade contra as parturientes é denunciada logo abaixo, no item 15 do Relatório Figueiredo. Juracy afirmou ainda que as índias mais jovens eram "examinadas" por um homem do SPI e o mesmo alegava procurar doenças venéreas, mas esses "exames" eram feitos sempre à noite, na sala do serviço médico do órgão (VALENTE, 2017).

\footnotetext{
${ }^{6}$ O livro Os Fuzis e as Flechas é uma investigação jornalística escrita por Rubens Valente, que descreve as violações de direitos humanos cometidas conta os povos indígenas no período da ditadura militar no Brasil. O livro foi escrito entre outubro de 2013 e setembro de 2015.
} 


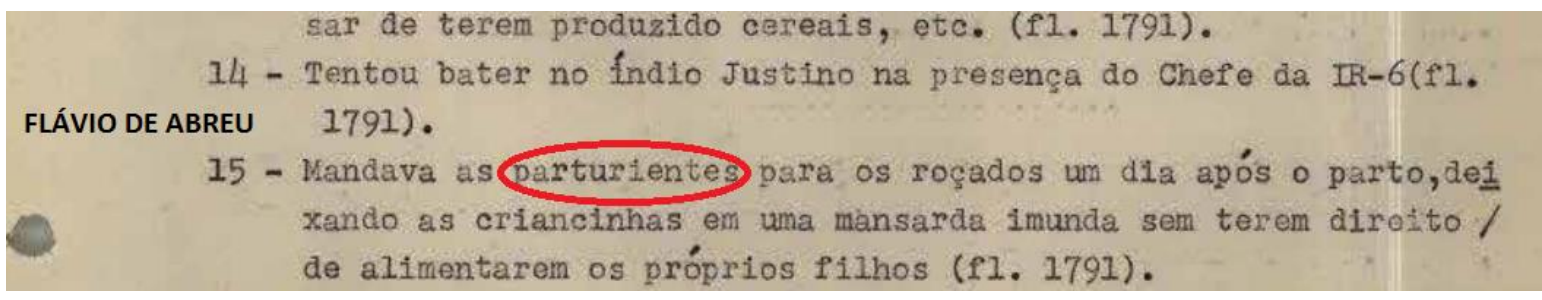

Fonte: RF Síntese, p. 27, grifos meus

Ainda sobre as indígenas grávidas, há o relato da índia Teriwari, que consta na pesquisa de Rubens Valente (2017), na qual afirma que os tiros no mato assustavam os índios e a proibição para caçar os deixava famintos, o que deixou sequelas físicas e psicológicas como abortos espontâneos.

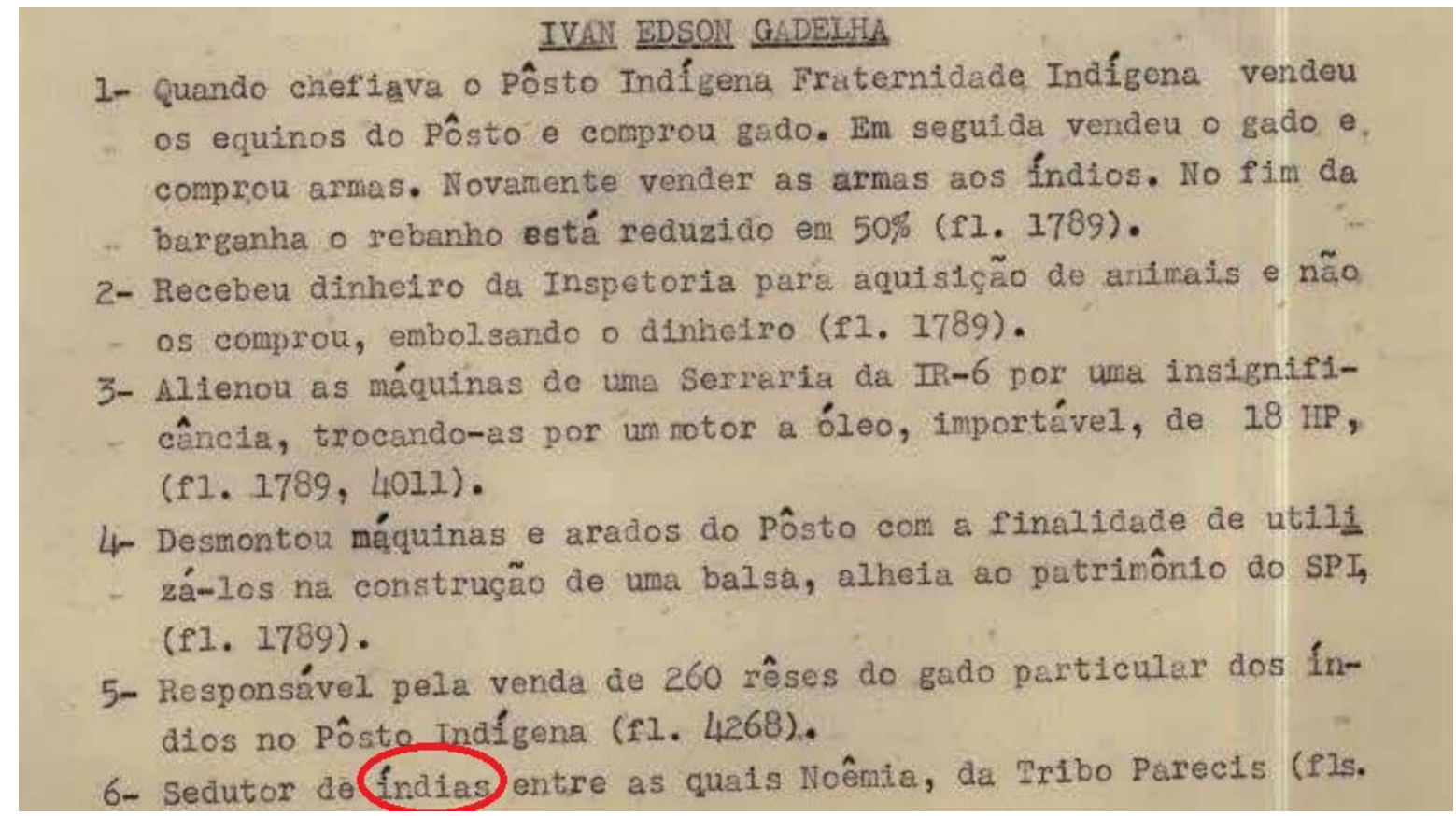

Fonte: RF Sintese, p. 36, grifos meus

O Rapto da índia Florisbela, citado entre os crimes de João Batista Corrêa, é um exemplo da afirmação de um dos entrevistados por Rubens Valente. $O$ entrevistado afirma que o ambiente do entorno das aldeias era de extremo perigo e que as mulheres eram assediadas à luz do dia. Os seringueiros também eram autores desses crimes e as mulheres evitavam o contato com eles (VALENTE, 2017, p. 29). 


\section{JOÃO BATIBTA CORBABA}

1- Espcancamento de índios com palmatórla (fls. 1505,1682).

2- Tentativa de enforcamento e, após penduramento pelos pulsos do garôto Ínđio Salico no Pôsto Indígena Fratermidade Indígena / (f1. 1681, 1682, 1793, 4014, 4292).

3- Exploração do trabalho indígena (fl. 1681).

4- Cárcere privado de índios (f1s. 4014,4292).

5- Destêrro de Índios do Pôsto para trabalhos em fazendas estranhas a título de castigo (f1. 1516).

6- Negociatas com terras indéfenas (fl. 1505).

7- Sedução de (indias) (f1. 1505, 1682).

8- Rapto da (India) Florisbela (fl. 1682).

Fonte: RF Síntese, p. 37, grifos meus

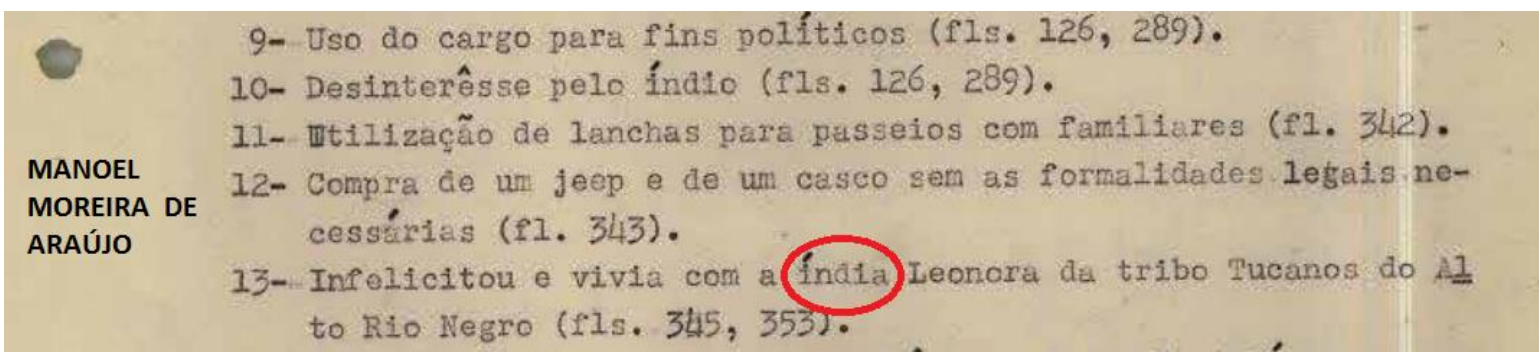

Fonte: RF Síntese, p. 50, grifos meus

\section{WISMGR COSPA LIMA}

1-Desrespetto@s mulhoregindías no Pôsto Indígena Barão de Antonina, mesmo durante o expedionte (fl. 1718, 1843).

2-No P.I. Solistre de Campos permitiu que o fndio Antonio olf́mpio fôsse amarrado el surrado a pau a ponto de fazê-lo fugir do Pôsto (r1. 1764).

3- vício de embriagûes (fls. 1718, 1843).

Fonte: RF Síntese, p. 67, grifos meus

Enfim, todas essas violências em tempos de Ditadura são violações correspondentes aos tempos de guerra, tais quais aborda Leymah Gbowee (2015), para quem os direitos das mulheres são questionados cotidianamente. Em tempos de guerra, tais mulheres perdem mesmo o direito à dignidade de se manterem enquanto mulheres. Muitas identidades femininas são postas em jugo e a vontade de não ser mulher 
é latente para livrar-se dessas violações. Mais que o corpo mutilado, mulheres indígenas sofrem com a violência, que resulta em questionamentos do porquê de seus sexos e identidades enquanto indígenas (SMITH, 2014).

\section{Mulheres Indígenas e o Relatório Final da Comissão Nacional da Verdade}

O Relatório Final, da Comissão Nacional da Verdade, publicado em 2014, pela Comissão Nacional da Verdade, e que também dá base para a construção teórica deste trabalho, foi e é de importância ímpar para que a sociedade conheça as violações de direitos humanos cometidas no período ditatorial brasileiro. Apesar disso, está passível de críticas.

Reconheço na leitura do mesmo que a mulher indígena, enquanto sujeito de sua história, continua sendo invisibilizada e tratada apenas como parte do todo, tal qual afirma Cristiane Lasmar:

[A]lém de estar diretamente ligada ao problema mais geral da hegemonia da perspectiva masculina nas ciências sociais, a invisibilidade das mulheres indígenas é um caso específico da invisibilidade dos próprios índios, categoria étnica e racial ainda atrelada, na visão do senso comum, a representações enraizadas em fontes remotas, e cuja elaboração inicial recua aos primeiros séculos da colonização do Novo Mundo (LASMAR, 1999, p. 3).

Afirmo isso pois, em todo o relatório, a mulher indígena enquanto ser violado é citada sete vezes. Talvez a preocupação de Maria Rita Kehl, elaboradora do texto temático intitulado Violações de Direitos Humanos dos Povos Indígenas, fosse mostrar um apanhado geral das violações aos povos indígenas. Mas reconheço que as implicações das violências cometidas contra as mulheres são diferentes e precisam ser tratadas em suas especificidades. Para isso, utilizei como método destacar os trechos em que aparece o termo "mulheres" e os transcrevi para análise de categorias do relatório.

Abaixo destaco o primeiro relato sobre mulheres no Relatório Final da Comissão Nacional da Verdade: 
Em março de 1985, um despejo na área conhecida como Jaguapiré expôs a vinculação direta de agentes da segurança pública com esses processos. Cerca de 30 homens atacaram os indígenas - incluindo-se vários policiais militares, que teriam sido convocados pelo prefeito de Tacuru. Uma das vítimas desse ataque, Silvio Benites, assim descreveu o episódio em depoimento ao antropólogo Kaiowá Tonico Benites: Ao cercar as nossas casas, [...] os policiais já dominaram e amarraram crianças, mulheres, homens, e carregaram na carroceria do caminhão. Além disso, começaram a lançar tiros sobre nós, chutaram nas pernas dos homens. A minha perna foi fraturada pelos jagunços, costela de meu irmão Amilto foi fraturado e desmaiado (2014, p. 216 , sic. grifos meus).

Segundo relato:

[O]s testemunhos Avá dão conta de que suas mulheres sofreram abusos sexuais, intimidação e, ao fim de dois anos, foram sumariamente transferidas para a aldeia dos seus inimigos históricos, os Javaé, que eram cerca de 300 pessoas na época, passando a viver, até hoje - com uma população de 23 pessoas -, em condições graves de submissão, marginalização social, econômica e política, sofrendo assédio moral nas situações de conflito e grandes restrições alimentares. $O$ Estado forçou a subordinação cotidiana dos Avá aos seus adversários históricos, de modo que os primeiros foram assimilados culturalmente pelos Javaé como cativos de guerra (2014, p. 228. grifos meus).

Destaquei os termos acima para caracterizar as violações, como violência de gênero. As categorias utilizadas mostram as diferentes opressões que o sujeito histórico mulher sofre.

Os trabalhadores da Transamazônica começaram a invadir a reserva e, durante esses contatos iniciais, temse notícia de que trabalhadores da estrada presenteavam os homens Parakanã e violentavam várias mulheres. Os relatos também dão conta de que os próprios agentes da Funai praticaram violências sexuais contra as mulheres. O relato do médico Antônio Madeiros, em 1971, é eloquente ao relatar esse "quadro de promiscuidade": 35 mulheres indígenas e dois agentes da Funai foram acometidos por doenças venéreas, oito crianças nasceram cegas e cerca de seis crianças morreram de disenteria (DAVIS, 1978, p. 94). Em 1979, a imprensa divulgou denúncias do antropólogo 
Antônio Carlos Magalhães, que na época trabalhava na Funai como coordenador do Projeto Parakanã, referentes a problemas na Frente de Atração durante a construção da Transamazônica em 1971. Segundo ele, 58 indígenas Parakanã teriam morrido de blenorragia ou pneumonia durante aquele período. As doenças teriam sido contraídas não somente pelo contato com trabalhadores da rodovia, como também, pelo contato com funcionários da Funai infectados (CNV, 2014, p. 230. grifos meus).

Os relatos de abusos e transmissão de doenças sexuais estão dentre as violações mais comuns que acometiam essas mulheres. E com isso percebo a construção de uma nação tipicamente masculina, como afirma Veena Das:

\begin{abstract}
[A]s violações inscritas no corpo feminino (literal e figurativamente) e as formações discursivas em torno dessas violações, como vimos, tornaram visível a imaginação da nação como uma nação masculina. O que isso fez à subjetividade das mulheres? Precisamos perguntar não só como a violência étnica ou comunal foi perpetrada por atos de violação específicos de gênero, como o estupro, mas também como as mulheres tomaram esses signos nocivos de violação e os reocuparam através do trabalho de domesticação, ritualização e re-narração (2008, p. 217).
\end{abstract}

Andrea Smith, enquanto mulher indígena, explica como a violência sexual se reverbera nessas mulheres, pois ela discute a diferenciação da violência sexual para homens e mulheres indígenas e afirma que a indígena quando violada sexualmente é atacada em sua identidade de indígena, como afirmado no tópico anterior. Ainda identifica que tais mulheres são consideradas sexualmente violáveis e estupráveis. Os índios não são considerados pessoas de verdade, por isso o "sucesso" da violência sexual.

Apesar de ser uma discussão em torno de mulheres indígenas dos EUA, identifico semelhanças nas violações cometidas contra mulheres indígenas no Brasil, especificamente no período ditatorial. Essa farsa desenvolvimentista que se deu no período da ditadura militar brasileira enaltecia uma ocupação das terras indígenas e a consequência disso era a violação de seus corpos. Andrea Smith afirma que "o projeto de prática de violência sexual nas colônias estabelece a ideologia de que os corpos 
indígenas são naturalmente violáveis - e, portanto, as terras indígenas também são naturalmente violáveis" (2014, p. 201).

E, para sustentar essa ideia de dominação e justificar a mesma usava-se (usa-se) o discurso dos corpos indígenas como inerentemente pecaminosos e sujos; ser índio é pecado e o abuso justificável. Com isso, os indígenas internalizam esse projeto genocida com a autodestruição, como afirma Andrea Smith (2014).

Os outros três relatos que destaquei foram os seguintes:

[A] Funai, no entanto, foi omissa frente à situação de calamidade enfrentada pelos Cinta Larga da região. Técnicos indigenistas revelaram que mulheres Cinta Larga da Aldeia Serra Morena, em Rondônia, estavam sendo prostituídas com a conivência dos funcionários da Funai do posto indígena da aldeia. Os denunciantes afirmaram que os próprios funcionários da Funai mantiveram relações com as índias e que a aldeia passou para um estágio de total dependência e abandono (CNV, 2014, p. 238).

De 1972 a 1974, durante as três operações que resultaram no desmantelamento da resistência guerrilheira que havia se instalado em pleno território Aikewara, todos os homens adultos desse povo foram forçados a guiar os militares nas expedições de captura dos guerrilheiros, por seu conhecimento das florestas da região, e as mulheres e crianças foram mantidas reféns em suas próprias casas, sendo impedidas de sair para colher alimentos nas roças (que também foram queimadas), para caçar, ou até mesmo para a satisfazer necessidades fisiológicas básicas (CNV, 2014, p. 246).

Em seus depoimentos prestados para o estudo entregue à CNV, mulheres e adultos que eram crianças à época relatam como o confinamento forçado resultou em todo tipo de privações, na fome generalizada e no terror psicológico de não saber o paradeiro dos homens adultos recrutados forçosamente (CNV, 2014, p. 246).

Fotografei o único relato em que uma mulher indígena aparece como interlocutora no Relatório Final da Comissão Nacional da Verdade (p. 246): 
Nascimentos prematuros e mortes de recém-nascidos por desnutrição ou outras causas relacionadas foram relatados. Destacamos parte do depoimento de Teriweri, ex-mulher de um dos índios que foram obrigados a guiar os militares nas matas:

Não sei o quê que foi que aconteceu? Eu num sei. Mas eu acho que tanto susto aí que nós pegava, né? Porque toda hora era tiro!! Toda hora!! Vento num podia balançar um matinho que eles atiravam! É!.. E a gente num podia ir pra roça mais também... porque eles [os militares] proibia! Porque às vezes, os "pessoal da mata"... [os guerrilheiros]... eles [os militares] falava que os "pessoal da mata" podia matar nós lá no mato né? Nós num podia caçar também... E aí nós falamo assim: Como é que nós vamo então sobreviver agora? Porque naquele tempo índio num fazia roçona grande, né? Era pouca... assim era só um pedacinho que eles fazia roça.., roçava e plantava mandioca. E aí num podia sair! Porque eu acho que por conta de tudo isso que aconteceu que eu tive assim... quase aborto, né? As crianças num viveram porque tanto medo que a gente passava, dos tiros, né? Então aconteceu isso com a gente, eu num gosto de me lembrar, sabe? Eu estou contando aqui pra vocês porque as pessoas assim... pode ser assim os povos do Brasil, do mundo todo, pra saber direito que aconteceu mesmo esse horrível acontecimento. É "guerra" né? No tempo da guerrilha, né? É por isso que eu estou contando aqui um pouco... ${ }^{148}$

Como se não bastasse o racismo imposto, ainda há o peso do machismo branco e patriarcal. Por isso, o enfoque sobre o ser mulher que é ao mesmo tempo reprodutora dos grupos humanos e principal ameaçada pelos grupos invasores. Ocupar terras requer ocupar corpos e então temos as mulheres como principais vítimas.

No entanto, é necessário, que não nos esqueçamos das diversas maneiras pelas quais as mulheres indígenas resistem a essas violações estatais. Há de se considerar suas agências, como afirma Camille Barata (2017), sempre pensar seu protagonismo frente às situações de precariedade e violência.

O protagonismo das mulheres indígenas, pensado como categoria de luta e resistência, corrobora o que diz Judith Butler (2011), quando afirma ser necessária uma ampliação das reivindicações sociais e políticas para que as vidas lesadas ou perdidas sejam consideradas vidas de fato. Neste caso, me refiro à vida das mulheres indígenas. Ela afirma:

[C]ontudo, quero demonstrar que, se queremos ampliar as reivindicações sociais e políticas sobre os direitos à proteção e o exercício do direito à sobrevivência e à prosperidade, temos antes que nos apoiar em uma nova ontologia corporal que implique repensar a precariedade, a vulnerabilidade, a dor, a interdependência, a exposição, a subsistência corporal, o desejo, o trabalho 
e as reivindicações sobre a linguagem e o pertencimento social (2011, p. 15).

Os documentos analisados comprovam que as categorias relacionadas a gênero foram e continuam sendo invisibilizadas e tratadas, apenas, como parte do todo. A mulher indígena, encarada como subalterna e violada de forma diferenciada, é impedida de ter seu lugar de fala ou manifestação. Ainda assim, se põe como resistência necessária ao combate de tanta dor.

\section{Concluindo}

As violações de Direitos no período ditatorial são inúmeras e não podem ser esquecidas ou apagadas e, portanto, precisam ser revistas. Este trabalho apresenta uma denúncia, na tentativa de produzir reflexão sobre tais casos. Afinal, é necessário que se tenha conhecimento da injustiça que se perpetua até os dias atuais contra esses povos. Como afirma Jane Beltrão (2007), para que a justiça seja efetivada é necessário trabalhar a diversidade cultural dos povos e o respeito à mesma, embasado em ética e tolerância. Caso contrário, torna-se impossível a conversa entre indígenas e não indígenas, necessária para o reparo de tanta dor.

A aproximação com os debates feministas me fez compreender a importância do enfoque no sujeito mulher, e entendo esta pesquisa como uma denúncia às violações de gênero, pautadas em uma construção de sociedade machista e branca. Pensar em como mulheres indígenas tiveram seus corpos violados e, consequentemente, suas identidades, é saber da necessidade de tratar tais casos e suas especificidades.

Os documentos analisados, os debates vividos e as autoras lidas me comprovaram a hipótese inicial de insivibilização e/ou marginalização das mulheres indígenas pelo Estado brasileiro. Os povos indígenas em sua totalidade sempre foram tratados como grupos à parte, não merecedores do direito básico e essencial à vida. As mulheres que sofrem o peso de três violações, a étnica, racial e de gênero, são, aos olhos do poder dominante, subalternas. 
Assim, mulheres indígenas e ditadura são uma discussão necessária e espero que outras pessoas se questionem acerca disso. Que mais mulheres indígenas sejam ouvidas como protagonistas e sujeitas de suas histórias, para fazermos, como Butler (2011) insiste, as reivindicações sobre o pertencimento social.

\section{Referências bibliográficas}

BARATA, Camille Gouveia Castelo Branco. Mulheres tembé-tenetehara: corporeidade, violências e intersecções. Qualificação apresentada ao Programa de PósGraduação em Antropologia, Universidade Federal do Pará - UFPA. Belém, 2017 (Inédito).

BELTRÃO, Jane Felipe. Laudo Antropológico da Área Indígena Sororó. Belém, 1998 (Inédito).

Conpedi, 2007. p. 3590-3608. Disponível em: <http://www.publicadireito.com.br/conpedi/manaus/arquivos/anais/bh/jane felipe beltr ao.pdf>. Acesso em 9 fev. 2017.

BRASIL. Comissão Nacional da Verdade (CNV). "Povos Indígenas e Ditadura Militar Subsídios à Comissão Nacional da Verdade 1946-1988”. In: Relatório Parcial 01, 30 nov. 2012. Disponível em: <https://idejust.files.wordpress.com/2012/12/povosindc3adgenas-e-ditadura-militar-relatc3b3rio-parcial-30_11_2012.pdf $>$. Acesso em 2 mar. 2016.

Relatório Figueiredo: documento na íntegra. Brasília, 2013. Disponível em: $\overline{<\text { http://racismoambiental.net.br/2013/06/02/relatorio-figueiredo-documento-na-integra- }}$ 7-mil-paginas-pdf-pode-agora-ser-baixado/>. Acesso em 2 mar. 2016.

Comissão Nacional da Verdade (CNV). Relatório da Comissão Nacional da Verdade, v. I. Brasília, 2014. Disponível em: 〈http://www.cnv.gov.br/images/pdf/relatorio/volume_1_digital.pdf $\rangle$. Acesso em 2 mar. 2016.

. Comissão Nacional da Verdade (CNV). Relatório da Comissão Nacional da Verdade, v. II. Brasília, 2014. Disponível em: 〈http://www.cnv.gov.br/images/pdf/relatorio/volume_2_digital.pdf $\rangle$. Acesso em 2 mar. 2016.

BUTLER, Judith. 2011. Vida precária. Contemporânea, São Carlos, v. 1, n. 1, p. 13-33, jan.-jun. 2011.

Disponível

em: 
$<$ http://www.contemporanea.ufscar.br/index.php/contemporanea/article/view/18/3> Acesso em 10 maio 2018.

DAS, Veena. El acto de presenciar: violencia, conocimiento envenenado y subjetividade. In: ORTEGA, Francisco (Org.). Veena Das: sujetos del dolor, agentes de dignidad. Bogotá: Universidad Nacional de Colombia, 2008. p. 343-374.

GBOWEE, Leymah. Guerreiras da Paz: como a solidariedade, a fé e o sexo mudaram uma nação em guerra - memórias. São Paulo: Cia das Letras, 2012.

JOFFILY, Mariana. 2016. Violências sexuais nas ditaduras militares latino-americanas: Quem quer saber? SUR, São Paulo, v. 13, n. 24, 2016. p. 165- 176. Disponível em: $<$ https://bdjur.stj.jus.br/jspui/bitstream/2011/108509/violencias_sexuais_ditaduras_joffil y.pdf $>$. Acesso em 10 maio 2018.

LASMAR, Cristiane. Mulheres indígenas: representações. Revista Estudos Feministas, Florianópolis, v. 7, n. 1 -2, p. 143-156, 1999. Disponível em: <https://periodicos.ufsc.br/index.php/ref/article/view/11989/11264>. Acesso em 5 ago. 2017.

LUGONES, María. Colonialidad y Género. Tabula Rasa, Bogotá, Colombia, n. 9, p. 73101, jul.-dec. 2008.

MALDONADO-TORRES, Nelson. Sobre la Colonialidad del Ser: contribuciones al desarrollo de um concepto. CONFERÊNCIA apresentada no Centro para Estudios de la Globalización em las Humanidades, Carolina do Norte, 2003.

QUIJANO, Aníbal. Colonialidad del poder, eurocentrismo y América Latina. In: LANDER, Edgardo (ed.). La Colonialidad del Saber: Eurocentrismo y Ciencias Sociales. Perspectivas Latinoamericanas, 2000. p. 201-245.

RODRÍGUEZ IBÁÑEZ, Mario. 2013. Resignificando la ciudad colonial y extractivista. In: GRUPO PERMANENTE DE TRABAJO SOBRE ALTERNATIVAS AL DESARROLLO. Alternativas al Capitalismo Colonialismo del siglo XXI. Quito: Abya Yala, 2013. p. 225-258. Disponível em: 〈https://fisyp.org.ar/media/uploads/alternativascapitalismoxxi_rosalux.pdf $>$. Acesso em 5 ago. 2017.

SMITH, Andrea. A violência sexual como uma ferramenta de genocídio. Espaço Ameríndio, Porto Alegre, v. 8, n. 1, p. 195-230, 2014. Disponível em: $<$ http://seer.ufrgs.br/index.php/EspacoAmerindio/article/view/47357/29960>. Acesso em 7 abr. 2017.

SPIVAK, Gayatri Chakravorty. Pode o subalterno falar? Belo Horizonte: Editora UFMG, 2010.

VALENTE, Rubens. Os fuzis e as flechas: história de sangue e resistência indígena na ditadura. São Paulo: Cia das Letras, 2017. 
Recebido em: 31/05/2018 * Aprovado em: 02/10/2018 * Publicado em: 29/12/2018 